\title{
Impacto da precipitação pluviométrica sobre a atividade de vôo de Plebeia remota (Holmberg, 1903) (Apidae, Meliponini)
}

\author{
Sergio Dias Hilário ${ }^{1,4}$, Márcia de Fátima Ribeiro ${ }^{2}$ \& Vera Lucia Imperatriz-Fonseca ${ }^{3}$ \\ Biota Neotropica v7 (n3) - http://www.biotaneotropica.org.br/v7n3/pt/abstract?article+bn02307032007 \\ Recebido em 11/06/07 \\ Versão Reformulada recebida em 12/09/06 \\ Publicado em 28/09/07 \\ ${ }^{1}$ Departamento de Zoologia, Instituto de Biociências, Universidade de São Paulo - USP, \\ Rua do Matão, tr. 14, n. 321, Cidade Universitária, CEP 05508-900, São Paulo, SP, Brasil \\ ${ }^{2}$ Embrapa Semi-Árido, BR 428 - Km 152, Zona Rural CP 23, CEP 56302-970, Petrolina, PE, Brasil \\ ${ }^{3}$ Departamento de Biologia, Faculdade de Filosofia Ciências e Letras de Ribeirão Preto, \\ Universidade de São Paulo - USP, Av. Bandeirantes, 3900, Monte Alegre, \\ CEP 14040-901, Ribeirão Preto, SP, Brasil \\ ${ }^{4}$ Autor para correspondência: Sergio Dias Hilário, e-mail: sedilar@usp.br
}

\begin{abstract}
Hilário, S.D., Ribeiro, M.F. \& Imperatriz-Fonseca, V.L. Rain effect on flight activity of Plebeia remota (Holmberg, 1903) (Apidae, Meliponini). Biota Neotrop. Sep/Dez 2007 vol. 7, no. 3 http://www.biotaneotropica. org.br/v7n3/pt/abstract?article+bn02307032007. ISSN 1676-0603.

Through an automated system, foragers' flight activity of four colonies of Plebeia remota was registered simultaneously from December 1998 to December 1999. The large amount of data obtained has allowed a quantitative and seasonal analysis of the rain impact on the bees' flight activity. The colonies came from two different localities: Cunha, Atlantic Rainforest in São Paulo State and Prudentópolis, Araucaria Forest in Paraná State. Percent numbers related to the flight activity for the moment that preceded the rain in one hour, as well as during and after the precipitation are presented. In all colonies, it was observed that the flight activity of P. remota has predominantly decreased before and during the precipitation. After it stopped raining, there was a predominance of increases, what indicates a compensation of flight activity in relation to the rainy period. In general, the greatest decrease of flight activity before rain, occurred in the autumn and the greatest increase of flight activity after rain, occurred in the spring. Alterations in this activity were observed with the variation of intensity, frequency and duration of precipitation. The external activity was little modified when the precipitation was up to $1.0 \mathrm{~mm}$. However, when the rain intensity increased, the bees reduced strongly their flight activity. When the rain occurred only once per day, the decreases in the flight activity were greater, when compared to intermittent rain. Rains that lasted more than one hour caused larger decreases in the flight activity than precipitations of short duration. Flight activity was quite different when we compared days with rain and days without rain, as well as, flight activity was differently influenced in rainy days in the summer and in the winter. However, this behavior (response of flight activity to rain) did not allow to discriminate both populations.
\end{abstract}

Keywords: flight activity, stingless bees, climatic factors, rain, foraging.

\section{Resumo}

Hilário, S.D., Ribeiro, M.F. \& Imperatriz-Fonseca, V.L. Impacto da precipitação pluviométrica sobre a atividade de vôo de Plebeia remota (Holmberg, 1903) (Apidae, Meliponini). Biota Neotrop. Sep/Dez 2007 vol. 7, no. 3 http://www.biotaneotropica.org.br/v7n3/pt/abstract?article+bn02307032007. ISSN 1676-0603.

Através de um sistema automatizado, a atividade do vôo de forrageiras de quatro colônias de Plebeia remota foi registrada ao mesmo tempo, de dezembro de 1998 a dezembro de 1999. Havia uma quantidade grande de dados que permitiram uma análise quantitativa e sazonal do impacto da pluviosidade sobre a atividade de vôo. As colônias vieram de duas localidades diferentes: Cunha, Mata Atlântica de São Paulo e Prudentópolis, Mata Araucária no Paraná. Números percentuais referentes à atividade de vôo para o momento que antecedia em uma hora a chuva, como também durante e após a precipitação, são apresentados. Em todas as colônias observaramse, predominantemente, decréscimos na atividade externa de P. remota, tanto antes como durante a precipitação. Após cessar a chuva, houve um predomínio de acréscimos, o que indica uma compensação da atividade de vôo em relação ao período chuvoso. De modo geral, o maior decréscimo de atividade de vôo, antes da chuva, ocorreu no outono e o maior acréscimo de atividade de vôo, depois da chuva, ocorreu na primavera. Alterações nesta atividade foram observadas com a variação da intensidade, freqüência e duração das precipitações pluviométricas. A atividade externa foi pouco alterada quando a precipitação foi de até 1,0 mm, mas com o aumento de intensidade, os valores de decréscimo nesta atividade aumentaram. Quando a precipitação ocorreu apenas uma vez por dia, os decréscimos na atividade de vôo foram maiores, comparados às chuvas intermitentes. Chuvas com duração maior que 1 hora causaram decréscimos maiores na atividade de vôo, do que precipitações de curta duração. A 
atividade do vôo foi bem diferente quando comparados dias com chuva e dias sem chuva, assim como a atividade do vôo foi influenciada diferentemente em dias chuvosos no verão e no inverno. Entretanto, este comportamento não permitiu discriminar as populações.

Palavras-chave: atividade de vôo, abelhas sem ferrão, fatores climáticos, precipitação pluviométrica, forrageamento.

\section{Introdução}

A atividade de vôo, também denominada atividade externa, é a contagem do número de abelhas que saem ou entram nas colméias, com ou sem material aparente. Esta atividade tem sido muito mais estudada nas abelhas sociais dos gênero Apis (Lundie 1925, Woyke 1992, Ellis et al. 2003, Huang \& Seeley 2003, Danka \& Beaman 2007) e Bombus (Morse 1982, Spaethe \& Weidenmüller 2002, Inoue et al. 2007). Na contagem de abelhas sem ferrão, Nogueira-Neto et al. (1959) foram os pioneiros ao registrarem o número de forrageiras em flores de café.

Nos últimos anos, a atividade de vôo das abelhas sem ferrão tem sido estudada em vários aspectos, verificando-se que ela pode ser influenciada por fatores climáticos, tais como: temperatura, intensidade luminosa, umidade relativa, chuva e vento (Fowler 1979, Mouga 1984, Inoue et al. 1985, Azevedo 1996, Contrera et al. 2004, Souza et al. 2006). Além disto, outros fatores, separados ou em conjunto, também podem afetar a atividade de vôo, como as condições internas da colônia (Hilário et al. 2000, Fidalgo \& Kleinert 2007), a divisão de tarefas (Biesmeijer \& Tóth 1998, Nunes-Silva 2007), a fisiologia e o tamanho das abelhas (Imperatriz-Fonseca et al. 1985), a temporização interna das abelhas (Mohammed \& Starr 1999, Bellusci \& Marques 2001, Hilário et al. 2003), a diapausa reprodutiva (Pick \& Blochtein 2002), a recompensa calórica do néctar (Roubik \& Buchmann 1984), a disponibilidade de recursos florais na natureza (Nagamitsu \& Inoue 2002, Pierrot \& Schlindwein 2003) ou em estufa (Bruijn et al. 1991, Bruijn \& Sommeijer 1997) e a sazonalidade (Heard \& Hendrikz 1993, Hilário \& Imperatriz-Fonseca 2002, Borges \& Blochtein 2005, Cortopassi-Laurino et al. 2007).

Nos trabalhos sobre a influência de fatores abióticos na atividade de vôo de abelhas, comumente é mencionado que a precipitação pluviométrica causa a interrupção da atividade externa (Oliveira 1973, Iwama 1977, Kleinert-Giovannini 1982) ou a diminuição desta atividade (Michener 1974, Sommeijer et al. 1983, KleinertGiovannini \& Imperatriz-Fonseca 1986, Roubik 1989, Hilário et al. 2001, Kajobe \& Echazarreta 2005). Entretanto, até o momento a influência da precipitação pluviométrica sobre a atividade de vôo não foi quantificada. Dois fatores teriam dificultado isto: 1) justamente pela reduzida atividade de vôo durante a chuva, os investigadores cessaram as observações; e 2) quando estas foram realizadas, os números de observações foram relativamente baixos para a detecção desta influência.

Entre os autores que estudaram a atividade de vôo em abelhas sem ferrão, somente Bellusci \& Marques (2001) e Eltz \& Vonend (2001) o fizeram por meio de contagem automatizada. Nós também utilizamos dispositivos eletrônicos que efetuaram a contagem contínua das abelhas na entrada das colônias. Isto juntamente com a obtenção de dados climáticos muito mais precisos, oriundos de estações meteorológicas (Buriolla 1988, Souza \& Gonçalves 1994, Cunha et al. 2001), possibilitaram uma investigação pormenorizada do efeito da chuva sobre a atividade de vôo, que será mostrada neste trabalho.

Neste trabalho é apresentada uma análise detalhada e quantificada da influência da precipitação pluviométrica, bem como de suas características, sobre a atividade de vôo de colônias de Plebeia remota, originárias de Cunha, SP e de Prudentópolis, PR. Uma abordagem comparativa foi utilizada, uma vez que estudos têm demonstrado diferenças comportamentais (Ribeiro et al. 2003), moleculares (Francisco 2002, Arias et al. 2003), químicas e morfológicas (Patrício \& Imperatriz-Fonseca 2004) entre estas duas populações e é sabido que duas diferentes linhagens de abelhas melíferas manifestam-se de maneira distinta em sua atividade de vôo perante a ocorrência de chuva (Roubik 1989).

\section{Material e Métodos}

Há cerca de 30 espécies de Plebeia s. str., distribuídas desde Sinaloa e Tamaulipas, México, até a província de San Luis, Argentina (Michener 2000). No Brasil, Plebeia remota é encontrada nos estados de São Paulo, Paraná, Santa Catarina e Rio Grande do Sul (Nogueira-Neto 1970). Estima-se que as colônias possuam entre 2000 a 5000 abelhas (Benthem et al. 1995), que pesam 8,4 $\pm 1,0 \mathrm{mg}$ (Hilário \& Imperatriz-Fonseca 2002).

Quatro colônias de Plebeia remota, duas provenientes de Prudentópolis, $\mathrm{PR}\left(25^{\circ} 13^{\prime} \mathrm{S}\right.$ e $\left.50^{\circ} 59^{\prime} \mathrm{O}\right)$ e duas provenientes de Cunha, SP $\left(23^{\circ} 05^{\prime} \mathrm{S}\right.$ e $\left.44^{\circ} 55^{\prime} \mathrm{O}\right)$, foram estudadas no Laboratório de Abelhas em São Paulo (Instituto de Biociências, Universidade de São Paulo: $23^{\circ} 33^{\prime}$ S e $46^{\circ} 43^{\prime}$ O). Daqui por diante, estas colônias serão mencionadas como $\operatorname{Pr} 1, \operatorname{Pr} 2, \operatorname{Pr} 3$ e $\operatorname{Pr} 4$, respectivamente. Há evidências moleculares (DNA mitocondrial e microssatélites) que sugerem que estes dois grupos de abelhas constituem duas unidades evolutivas independentes (Francisco 2002, Arias et al. 2003). Há diferenças também na duração da diapausa reprodutiva (Ribeiro et al. 2003), na composição de secreções das glândulas de Dufour e na morfologia externa do escutelo (Patrício \& Imperatriz-Fonseca 2004).

Com a finalidade de estudar a atividade de vôo das abelhas, todos os indivíduos que entraram e saíram das colônias foram registrados através de fotocélulas colocadas em tubos plásticos, os quais serviam como acesso das abelhas para o ambiente externo do laboratório. Estes sensores eram conectados a um computador por meio de um controlador lógico programável (PLC: programmable logic controller Klockner-Möeller). Dados de atividade de vôo de 281 dias foram registrados entre 23/12/98 e 22/12/99 e separados para análise, segundo as estações do ano. Os horários de aurora e crepúsculo foram obtidos do Observatório Naval dos Estados Unidos (http://aa.usno.navy.mil/). Estes horários permitiram a delimitação do período de possível ocorrência de atividade de forrageamento de $P$. remota. Assim, dados de atividade de vôo de 3829 horas foram obtidos simultaneamente para as quatro colônias.

As colônias das abelhas sem ferrão podem ser classificadas segundo o número estimado de abelhas, peso das abelhas, tamanho do favo de cria e volume dos potes de alimento (Lacerda et al. 1991, Benthem et al. 1995). O número de vôos foi utilizado para classificar as colônias de $P$. remota, já que este número é relacionado ao tamanho populacional. As colônias não receberam alimentação adicional e o as condições ambientais não foram controladas. Os dados de precipitação foram obtidos do Laboratório de Climatologia e Biogeografia do Departamento de Geografia, Faculdade de Filosofia, Letras e Ciências Humanas - FFCLH, Universidade de São Paulo. Para verificar se a relação entre pluviosidade e outros fatores climáticos variava segundo as estações do ano, utilizamos dados climáticos (temperatura, umidade 
relativa, radiação solar, velocidade e direção do vento), também obtidos do LCB. Dados da pressão barométrica foram obtidos do Departamento de Ciências Atmosféricas, Instituto de Astronomia, Geofísica e Ciências Atmosféricas - IAG, Universidade de São Paulo.

Como o tamanho populacional das colônias foi diferente, a análise requereu uma padronização que será explicada em pormenores. Para exemplificar como as análises foram realizadas, utilizaremos um evento real. No dia 23 de março de 1999, choveu 11,4 mm das 11:00 horas às 12:59 horas. Para calcular o efeito dessa precipitação sobre a atividade de vôo das abelhas da colônia Pr4, dividimos inicialmente o número de vôos das 10:00 horas (2221) pelo número de vôos das 09:00 horas (2953). Do quociente obtido $(0,7521)$ retirou-se 1,0000 e daí resultou o valor $-0,2479$, que correspondeu ao momento que antecedeu em uma hora a chuva. Por meio de cálculo similar entre o número de vôos das 11:00 horas (874) e o número de vôos das 10:00 horas, obteve-se o número $(-0,6065)$ relativo ao momento durante a chuva. A razão entre o número de vôos das 13:00 horas (3538) e o número de vôos das 12:00 horas (2486) forneceu o valor $(0,4231)$ relativo ao momento após a precipitação. Os valores antecedidos do sinal negativo (-) indicariam decréscimos e o valor positivo, acréscimo na atividade de vôo.

Porém estes números refletiram tão somente o padrão de atividade de vôo das abelhas da colônia Pr4 do dia 23/03/1999. Os valores poderiam ter sido decorrentes de alterações próprias do padrão diário de atividade de vôo e não resultantes do efeito da precipitação. Portanto, houve necessidade de deduzir destes valores, para os mesmos horários, os valores médios do padrão diário da atividade de vôo das abelhas da colônia Pr4, relativos aos dias não chuvosos da mesma estação. No outono de 1999, os horários e as médias dos números de vôos foram: 09:00 horas, 2293,2; 10:00 horas, 2625,4; 11:00 horas, 2927,6; 12:00 horas, 2998,9 e 13:00 horas, 3312,3. Os valores deduzidos foram: 0,1449 (antes da chuva), 0,1151 (durante a chuva) e 0,1045 (depois da chuva). Daí resultaram os valores finais $-0,3928,-0,7216$ e 0,3187 , que indicaram decréscimos na atividade de vôo nos momentos antes e durante a chuva e acréscimo depois da precipitação, respectivamente.

No caso de precipitação prolongada, utilizou-se o valor relativo apenas ao primeiro horário com chuva, já que a habituação das abelhas com a chuva produz resultados bem diferentes do primeiro impacto da precipitação sobre a atividade de vôo. Após todas as análises, dia a dia, os resultados foram tabulados segundo as estações e as características da chuva (intensidade, duração, freqüência e hora de ocorrência). Assim, o evento do dia 23/03/99 foi inserido em diferentes categorias e classes: estação outono, intensidade acima de 10,0 mm, freqüência de mais que uma vez por dia (nesse dia choveu também entre 15:00 e 16:00 horas e entre 18:00 e 19:00 horas), duração de mais que uma hora. Quanto à hora de ocorrência, os valores dos momentos "antes da chuva" e "depois da chuva" entraram na classe "das 09:00 às 12:59 horas", enquanto que o momento "depois da chuva" foi inserido na classe "das 13:00 às 16:59 horas".

Após a tabulação e cálculo das médias, estes números serviram para a montagem da Tabela 1. Ela mostra estas médias, transformadas em porcentagens, para os momentos antes, durante e depois da precipitação pluviométrica, nas quatro colônias. A tabela foi subdividida a fim de verificar se estas porcentagens variavam conforme as estações e as características da chuva. Os números positivos e negativos indicam, respectivamente, as porcentagens de acréscimo e decréscimo na atividade de vôo.

Da razão entre as séries horárias da atividade de vôo de dias chuvosos com a de dias não chuvosos, obtivemos quocientes para cada horário. Destes, subtraímos 1,0000 e os resultados foram transformados em porcentagens. Para cada estação (verão, outono, inverno e primavera), estes valores e a precipitação total horária possibilitou a construção de gráficos (Figuras 1 a 4 , respectivamente). O dia chuvoso correspondeu a qualquer dia em que houve precipitação, não importando a intensidade, a frequiência ou a duração da mesma e, obviamente, o dia não chuvoso àquele onde não houve qualquer precipitação. Porcentagens positivas significaram que houve acréscimos na atividade de vôo em dias chuvosos em comparação aos dias não chuvosos. Por outro lado, porcentagens negativas indicaram decréscimos na atividade de vôo em dias chuvosos em relação à atividade de vôo de dias não chuvosos. Por simplicidade, daqui em diante, nós mencionaremos esta situação como porcentagem dc-dnc.
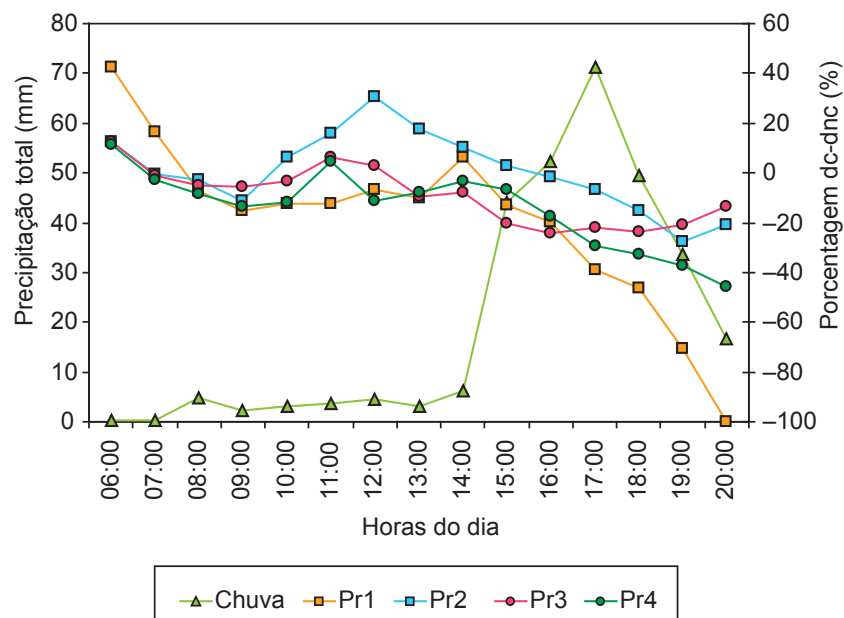

Figura 1. Precipitação total e as porcentagens resultantes da razão entre as médias da atividade de vôo de todas as colônias de Plebeia remota em dias chuvosos $(\mathrm{dc} ; \mathrm{n}=31)$ e em dias não chuvosos $(\mathrm{dnc} ; \mathrm{n}=32)$, no verão, segundo as horas do dia.

Figure 1. Total precipitation and the resultant percentages of the ratio between the flight activity means of all colonies of Plebeia remota in rainy days (dc; $\mathrm{n}=31)$ and in non-rainy days $(\mathrm{dnc} ; \mathrm{n}=32)$, in the summer, related to the time of the day.

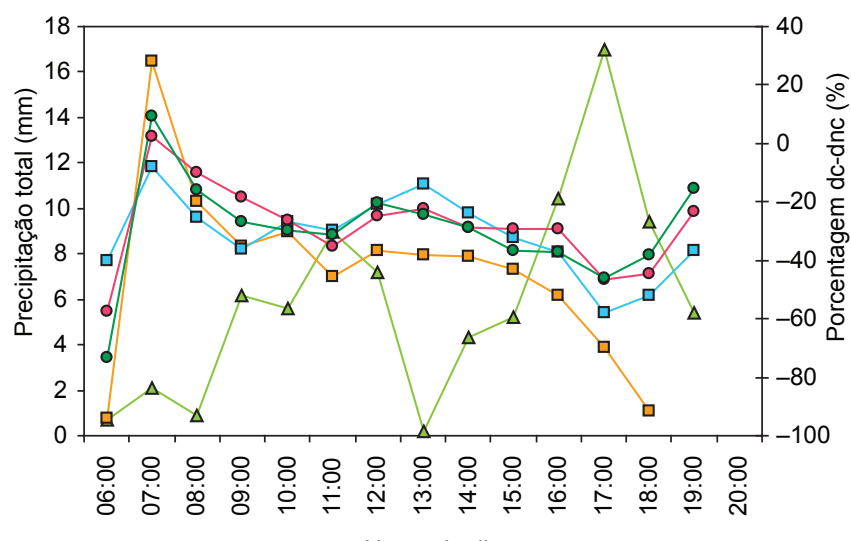

Horas do dia

$$
\triangle \text { Chuva }- \text {-Pr1 }- \text {-Pr2 } \rightarrow-\operatorname{Pr} 3 \rightarrow-\operatorname{Pr} 4
$$

Figura 2. Precipitação total e as porcentagens resultantes da razão entre as médias da atividade de vôo de todas as colônias de Plebeia remota em dias chuvosos (dc; $n=16)$ e em dias não chuvosos (dnc; $n=59)$, no outono, segundo as horas do dia.

Figure 2. Total precipitation and the resultant percentages of the ratio between the flight activity means of all colonies of Plebeia remota in rainy days (dc; $\mathrm{n}=16$ ) and in non-rainy days $(\mathrm{dnc} ; \mathrm{n}=59)$, in the autumn, related to the time of the day. 


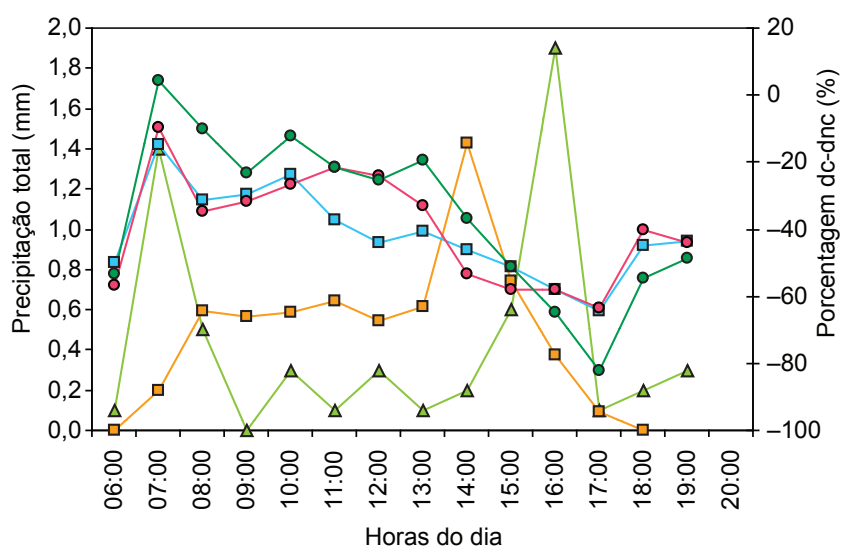

$$
\triangle \text { Chuva } \rightarrow-\operatorname{Pr} 1 \rightarrow-\operatorname{Pr} 2 \rightarrow-\operatorname{Pr} 3 \rightarrow-\operatorname{Pr} 4
$$

Figura 3. Precipitação total e as porcentagens resultantes da razão entre as médias da atividade de vôo de todas as colônias de Plebeia remota em dias chuvosos $(\mathrm{dc} ; \mathrm{n}=17)$ e em dias não chuvosos $(\mathrm{dnc} ; \mathrm{n}=64)$, no inverno, segundo as horas do dia.

Figure 3. Total precipitation and the resultant percentages of the ratio between the flight activity means of all colonies of Plebeia remota in rainy days (dc; $\mathrm{n}=17$ ) and in non-rainy days ( $\mathrm{dnc} ; \mathrm{n}=64)$, in the winter, related to the time of the day.

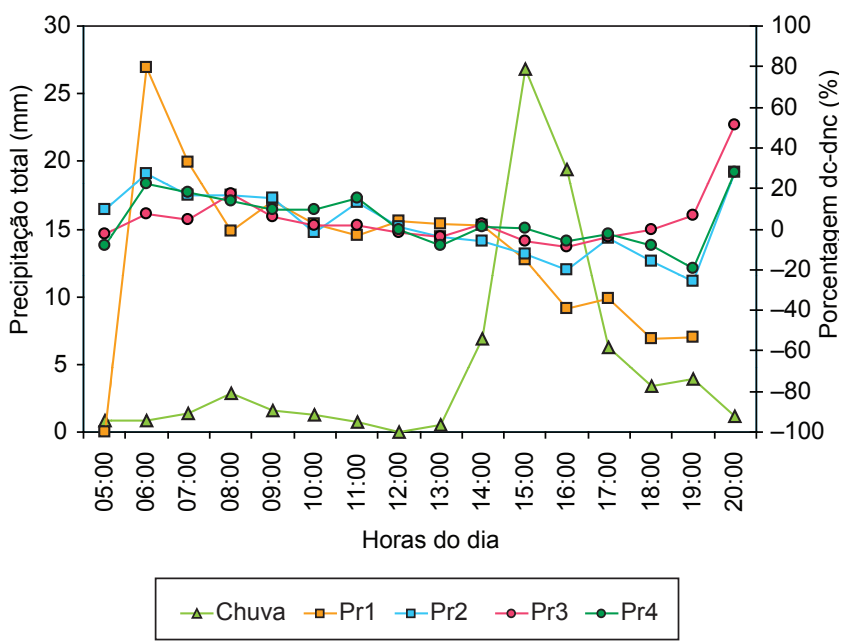

Figura 4. Precipitação total e as porcentagens resultantes da razão entre as médias da atividade de vôo de todas as colônias de Plebeia remota em dias chuvosos $(\mathrm{dc} ; \mathrm{n}=23$ ) e em dias não chuvosos (dnc; $n=37)$, na primavera, segundo as horas do dia.

Figure 4. Total precipitation and the resultant percentages of the ratio between the flight activity means of all colonies of Plebeia remota in rainy days (dc; $\mathrm{n}=23$ ) and in non-rainy days (dnc; $\mathrm{n}=37$ ), in the spring, related to the time of the day.

Tabela 1. Efeito das características da chuva sobre a atividade de vôo das colônias Pr1, Pr2 (de Prudentópolis, PR), Pr3 e Pr4 (de Cunha, SP), de Plebeia remota. Números positivos e negativos indicam, respectivamente, a porcentagem de acréscimo e decréscimo na atividade de vôo, antes (An), durante (Du) e depois (De) da chuva.

Table 1. Effect of rain characteristics on flight activity of Plebeia remota colonies Pr1 and Pr2 (from Prudentópolis, PR) and Pr3 and Pr4 (from Cunha, SP). Positive and negative numbers indicate percentage of increasing and decreasing in flight activity, respectively, before (An), during (Du) and after (De) the rain.

\begin{tabular}{|c|c|c|c|c|c|c|c|c|c|c|c|c|}
\hline \multirow[t]{2}{*}{ Características da chuva } & \multicolumn{3}{|c|}{ Colônia Pr1 } & \multicolumn{3}{|c|}{ Colônia Pr2 } & \multicolumn{3}{|c|}{ Colônia Pr3 } & \multicolumn{3}{|c|}{ Colônia Pr4 } \\
\hline & An $(\%)$ & Du $(\%)$ & De $(\%)$ & An $(\%)$ & Du $(\%)$ & $\operatorname{De}(\%)$ & $\operatorname{An}(\%)$ & Du $(\%)$ & De $(\%)$ & An (\%) & Du $(\%)$ & De $(\%)$ \\
\hline \multicolumn{13}{|c|}{ 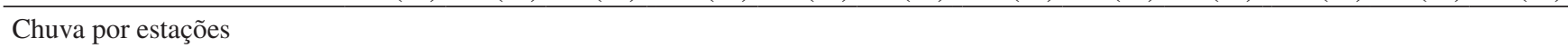 } \\
\hline Verão & $-30,9$ & $-24,2$ & 0,1 & 14,0 & $-10,8$ & $-3,0$ & $-11,1$ & $-9,6$ & 2,1 & $-0,9$ & $-13,9$ & $-0,6$ \\
\hline Outono & $-45,2$ & $-42,4$ & 113,5 & $-45,3$ & 8,0 & 26,3 & $-37,7$ & 13,5 & $-8,2$ & $-21,4$ & $-10,8$ & 35,4 \\
\hline Inverno & $-34,1$ & $-21,2$ & 45,1 & $-9,7$ & 7,9 & 2,7 & 6,8 & $-13,5$ & $-6,5$ & $-6,7$ & $-6,1$ & $-9,3$ \\
\hline Primavera & $-0,8$ & $-35,9$ & 25,7 & $-5,3$ & $-12,0$ & 32,4 & 8,1 & $-4,5$ & 19,7 & $-7,5$ & $-7,9$ & 47,1 \\
\hline \multicolumn{13}{|l|}{ Intensidade da chuva } \\
\hline Até $1,0 \mathrm{~mm}$ & $-24,9$ & $-10,1$ & 35,5 & $-3,4$ & 3,2 & 10,7 & 1,1 & 3,7 & 1,8 & 0,5 & 0,4 & 10,4 \\
\hline De 1,0 a $10,0 \mathrm{~mm}$ & $-28,2$ & $-26,4$ & 21,5 & $-5,0$ & $-1,7$ & 17,7 & $-16,2$ & $-8,9$ & 7,0 & $-13,7$ & $-13,1$ & 32,0 \\
\hline Acima de $10,0 \mathrm{~mm}$ & $-19,4$ & $-77,1$ & 58,3 & $-10,0$ & $-42,0$ & 12,3 & $-23,4$ & $-33,2$ & 6,0 & $-26,9$ & $-47,8$ & 0,3 \\
\hline \multicolumn{13}{|l|}{ Frequiência da chuva } \\
\hline Uma vez por dia & $-23,7$ & $-39,5$ & 36,3 & $-5,7$ & $-12,1$ & 27,0 & $-15,3$ & $-7,7$ & 10,6 & $-13,8$ & $-19,8$ & 15,0 \\
\hline Mais que uma vez por dia & $-26,4$ & $-19,0$ & 27,6 & $-3,8$ & 1,4 & 2,0 & 1,3 & $-3,2$ & $-1,9$ & 0,0 & $-2,6$ & 18,7 \\
\hline \multicolumn{13}{|l|}{ Duração da chuva } \\
\hline Uma hora & $-18,6$ & $-9,6$ & 16,2 & 10,7 & 6,2 & 12,2 & 8,2 & $-2,3$ & $-0,4$ & 5,5 & $-0,3$ & 12,8 \\
\hline Mais que uma hora & $-32,7$ & $-46,1$ & 56,7 & $-24,2$ & $-17,2$ & 14,3 & $-26,2$ & $-8,6$ & 9,4 & $-23,2$ & $-21,7$ & 23,2 \\
\hline \multicolumn{13}{|l|}{ Hora de ocorrência da chuva } \\
\hline Das 05:00 às 08:59 horas & $-137,6$ & $-33,5$ & 55,6 & $-37,2$ & $-14,0$ & 7,8 & $-42,0$ & $-30,6$ & $-12,6$ & 27,7 & $-25,9$ & 23,3 \\
\hline Das 09:00 às 12:59 horas & $-57,6$ & 8,8 & 75,9 & $-20,0$ & 23,0 & 25,1 & $-0,6$ & 7,3 & 17,4 & $-14,9$ & 5,5 & 34,8 \\
\hline Das 13:00 às $16: 59$ horas & $-8,5$ & $-39,0$ & 19,1 & $-2,4$ & $-14,0$ & 5,5 & $-14,6$ & $-16,4$ & $-6,5$ & $-11,7$ & $-16,5$ & 4,1 \\
\hline Das 17:00 às 20:59 horas & $-20,0$ & $-29,4$ & 9,1 & 2,4 & $-7,4$ & 15,5 & $-0,6$ & 4,6 & 13,9 & $-3,4$ & $-8,8$ & 14,5 \\
\hline
\end{tabular}

Em face das variáveis terem tido uma distribuição não-normal, todos os testes estatísticos utilizados foram de natureza não-paramétrica. As comparações estatísticas (testes de Kruskal-Wallis) da influência da precipitação pluviométrica sobre a atividade de vôo foram realizadas utilizando-se os dados brutos e separando-se os efeitos da chuva segundo suas características diárias (intensidade, frequiência, duração, hora de ocorrência) e as estações do ano. Para verificar se havia relação entre a precipitação e os outros fatores 
climáticos segundo as estações, realizamos testes de correlação de Spearman. Testes de Tukey para comparações múltiplas (Zar 1999) foram realizados com a finalidade de verificar se as colônias provenientes de Prudentópolis ( $\operatorname{Pr} 1$ e Pr2) poderiam ser separadas das de Cunha $(\operatorname{Pr} 3$ e $\operatorname{Pr} 4)$, segundo as suas atividades de vôo em relação à intensidade da chuva.

\section{Resultados}

A média diária do número de vôos, durante o experimento, foi: 6763 (colônia Pr1), 19087 (colônia Pr2), 20322 (colônia Pr3) e 25595 (colônia Pr1). Estes números mostram o tamanho relativo destas colônias.

Em todas as colônias (Tabela 1), observou-se um predomínio de decréscimos na atividade de vôo, tanto antes como durante a precipitação. Todavia, após a cessação desta, houve um predomínio de acréscimos (terceira coluna para cada colônia na Tabela 1), o que indica uma compensação da atividade de vôo em relação ao período chuvoso. Houve diferenças significativas entre as atividades de vôo relativas às horas sem precipitação e às horas que antecedem à chuva (em uma hora), durante e após a chuva (colônia Pr1: $\mathrm{H}=138,1$; colônia Pr2: $H=98,3$; colônia Pr3: $H=107,9$; colônia Pr4: $H=133,2$; $\mathrm{p}=0,0001$ para todos os testes).

\section{Estações do ano}

O maior decréscimo de atividade de vôo em todas as colônias, antes da chuva, ocorreu no outono. Durante a chuva, houve decréscimos na atividade externa de todas as colônias, tanto no verão como na primavera (Tabela 1), porém alguns acréscimos ocorreram (inverno e outono, colônia Pr2; outono, colônia Pr3). Exceto na colônia Pr1, o maior acréscimo de atividade de vôo, depois da chuva, ocorreu na primavera. Depois da chuva, as porcentagens de acréscimos (colônias Pr1 e Pr3) ou decréscimos (colônias Pr2 e Pr4; Tabela 1) foram baixas no verão. A precipitação total variou segundo as estações (verão: 295,3 mm; outono: 83,6 mm; inverno: 6,1 mm; primavera: 78,1 mm). Outros fatores climáticos, como a temperatura, por exemplo, podem ter colaborado para os valores obtidos.

A precipitação pluviométrica e suas características diferiram significativamente, segundo as estações do ano (precipitação: $\mathrm{H}=94,7$; intensidade: $H=96,8$; frequiência: $H=269$,8; duração: $H=295,0 ; p=$ 0,0001 para todos os testes). Entretanto, não houve diferença significativa para a hora de ocorrência: $(H=6,4 ; \mathrm{p}=0,0907)$. Diferenças significativas ocorreram entre as atividades de vôo relativas às estações do ano (colônia $\operatorname{Pr} 1$ : $\mathrm{H}=343,4$; colônia $\operatorname{Pr} 2: \mathrm{H}=35,7$; colônia Pr3: $\mathrm{H}=131,6$; colônia $\operatorname{Pr} 4: \mathrm{H}=68,3 ; \mathrm{p}=0,0001$ para todos os testes).

\section{Intensidade da chuva}

A atividade de vôo das colônias $\operatorname{Pr} 2, \operatorname{Pr} 3$ e Pr4 (Tabela 1) sofreram poucas alterações (porcentagens baixas), antes e durante as chuvas de até $1,0 \mathrm{~mm}$ de intensidade. Na colônia Pr1 (Tabela 1), o decréscimo da atividade de vôo antes da chuva oscilou de 19,4 até $28,2 \%$, independentemente da intensidade da precipitação. Durante a chuva, a atividade de vôo diminuiu ainda mais com o aumento da intensidade da precipitação. Esta situação também ocorreu para as colônias $\operatorname{Pr} 2, \operatorname{Pr} 3$ e $\operatorname{Pr} 4$ (Tabela 1), tanto antes como durante a precipitação. Estas colônias tiveram maior acréscimo na atividade de vôo, quando a intensidade das chuvas esteve entre 1,0 e 10,0 mm. Somente a colônia Pr1 teve maior acréscimo na atividade de vôo após a precipitação com intensidade acima de $10,0 \mathrm{~mm}$.

Houve diferença significativa entre a atividade de vôo e as diferentes categorias de intensidade de chuva (sem chuva; até 1,0 mm; entre 1,0 e 10,0 mm; acima de 10,0 mm) (colônia $\operatorname{Pr} 1: \mathrm{H}=133,4$; colônia Pr2: $H=104,0$; colônia Pr3: $H=106,6$; colônia Pr4: $H=130,8$; $\mathrm{p}=0,0001$ para todos os testes).

\section{Freqüência da chuva}

Combinados os efeitos de antes e durante a chuva, como mencionados nas colunas da Tabela 1 , houve maior decréscimo na atividade de vôo de todas as colônias, quando a precipitação ocorreu apenas uma vez por dia. Nesta mesma freqüência de pluviosidade, também ocorreu, depois da chuva, o maior acréscimo na atividade de vôo das colônias Pr1, Pr2 e Pr3 (Tabela 1).

Houve diferença significativa entre a atividade de vôo e as diferentes frequiências (sem chuva; chuva uma vez por dia; chuva mais que uma vez por dia) (colônia $\operatorname{Pr} 1$ : $H=24,7$; colônia $\operatorname{Pr} 2: H=47,3$; colônia $\operatorname{Pr}$ : $\mathrm{H}=33,3$; colônia Pr4: $\mathrm{H}=47,9 ; \mathrm{p}=0,0001$ para todos os testes).

\section{Duração da chuva}

Chuvas de curta duração (até 1 hora) causaram efeitos diversos nas atividades de vôo das colônias: acréscimos antes (colônias Pr2, Pr3 e Pr4) e durante (colônia Pr2) a chuva, e decréscimos depois da precipitação (colônia Pr3). Contudo, foram claros os decréscimos maiores em todas as colônias, antes e durante a chuva, quando a duração da chuva excedeu uma hora. Acréscimos na atividade de vôo, depois de chuva mais duradoura, foram maiores em todas as colônias.

Diferenças significativas foram observadas entre as atividades de vôo e as diferentes durações (sem chuva; até uma hora de chuva; mais que uma hora de chuva) (colônia $\operatorname{Pr} 1: \mathrm{H}=26,0$; colônia $\operatorname{Pr} 2$ : $\mathrm{H}=51,1$; colônia Pr3: $H=27,9$; colônia $\operatorname{Pr} 4: H=49,0 ; p=0,0001$ para todos os testes).

\section{Hora de ocorrência da chuva}

Os maiores decréscimos na atividade de vôo, antes e durante a chuva, ocorreram nas primeiras horas da manhã em todas as colônias, exceto a colônia $\operatorname{Pr} 4$ (antes da chuva, houve acréscimo) e a colônia Pr1 (durante a chuva). Os maiores acréscimos na atividade de vôo,

Tabela 2. Coeficientes de correlação de Spearman $\left(\mathrm{r}_{\mathrm{s}}\right)$ entre a precipitação e outros fatores climáticos (temperatura do ar, umidade relativa do ar, pressão barométrica, radiação solar e velocidade do vento), para as estações do ano. O valor da probabilidade (p), em negrito, indica que a correlação foi significativa.

Table 2. Spearman correlation coefficients $\left(r_{s}\right)$ between precipitation and other climatic factors (air temperature, relative humidity, barometric pressure, solar radiation and wind speed), for all seasons. The probability value (p), in bold print, indicates that the correlation was significant.

\begin{tabular}{|c|c|c|c|c|c|c|c|c|}
\hline \multirow[t]{2}{*}{ Fatores climáticos } & \multicolumn{2}{|c|}{ Verão } & \multicolumn{2}{|c|}{ Outono } & \multicolumn{2}{|c|}{ Inverno } & \multicolumn{2}{|c|}{ Primavera } \\
\hline & $\mathbf{r}_{\mathrm{s}}$ & $\mathbf{p}$ & $\mathbf{r}_{\mathrm{s}}$ & $\mathbf{p}$ & $\mathbf{r}_{\mathrm{s}}$ & $\mathbf{p}$ & $\mathbf{r}_{\mathrm{s}}$ & $\mathbf{p}$ \\
\hline Temperatura & $-0,362$ & 0,0001 & $-0,232$ & 0,0001 & $-0,107$ & 0,0005 & $-0,070$ & 0,0363 \\
\hline Umidade relativa & 0,524 & 0,0001 & 0,389 & 0,0001 & 0,137 & 0,0001 & 0,324 & 0,0001 \\
\hline Pressão barométrica & $-0,105$ & 0,0013 & $-0,137$ & 0,0001 & 0,000 & 0,9760 & $-0,107$ & 0,0013 \\
\hline Radiação solar & $-0,332$ & 0,0001 & $-0,250$ & 0,0001 & $-0,070$ & 0,0216 & $-0,187$ & 0,0001 \\
\hline Velocidade do vento & $-0,165$ & 0,0001 & $-0,166$ & 0,0001 & 0,080 & 0,0094 & $-0,149$ & 0,0001 \\
\hline
\end{tabular}


depois da chuva, ocorreram entre as 9:00 e 12:59 horas. Nesta mesma faixa de horário, chamou atenção os acréscimos na atividade de vôo de todas as colônias, durante a chuva. A precipitação total variou de acordo com as horas do dia (05:00 às 08:59 horas, 17,1 mm; 09:00 às 12:59 horas, $46,0 \mathrm{~mm}$; 13:00 às 16:59 horas, 181,9 mm; 17:00 às 20:59 horas, $218,1 \mathrm{~mm}$ ).

Houve diferença significativa nas atividades de vôo quando relacionadas às horas sem precipitação e às horas equivalentes com chuva (colônia Pr1: H = 1143,7; colônia Pr2: H = 998,3; colônia Pr3: H = 1204,8; colônia Pr4: $\mathrm{H}=1181,1 ; \mathrm{p}=0,0001$ para todos os testes).

\section{Relação da precipitação pluviométrica com os outros fatores climáticos}

Houve correlações entre a precipitação pluviométrica e os outros fatores climáticos (temperatura, umidade relativa do ar, pressão barométrica, radiação solar e velocidade do vento), para as quatro estações do ano (Tabela 2). Todas as correlações foram significativas, exceto entre a precipitação e a pressão barométrica, no inverno. Os maiores coeficientes de correlação foram aqueles entre a precipitação pluviométrica e a umidade relativa, para todas as estações. Entretanto, o segundo maior coeficiente de correlação de Spearman $\left(r_{s}\right)$ variou em cada estação: no verão e no inverno, foram aqueles entre a precipitação e a temperatura; no outono e na primavera, foram aqueles entre a precipitação e a radiação solar.

\section{Dias chuvosos versus dias não chuvosos}

No verão (Figura 1), até as 14:00 horas, a porcentagem dc-dnc teve médias: 0,2 (col. Pr1), 8,7 (col. Pr2), $-1,2$ (col. Pr3) e $-4,8$ (col. Pr4). O aumento da precipitação, a partir das 15:00 horas, provocou a diminuição da atividade de vôo e, conseqüentemente, da porcentagem dc-dnc com médias -48,0 (col. Pr1), -11,5 (col. Pr2), $-20,8$ (col. Pr3) e -28,2 (col. Pr4).

No outono (Figura 2), o pico de porcentagem dc-dnc ocorreu às 07:00 horas, já que as precipitações entre as 06:00 e 08:00 horas foram relativamente pequenas. Entretanto, no resto do dia, com o aumento da precipitação, a porcentagem dc-dnc ficou sempre abaixo de $0 \%$ para todas as colônias. Um pequeno platô pode ser notado às 13:00 horas, justamente o horário de menor precipitação na estação.

No inverno (Figura 3), a porcentagem dc-dnc sempre esteve abaixo de $0 \%$, exceto às 07:00 horas na colônia $\mathrm{Pr} 4$. O primeiro pico de precipitação, às 07:00 horas, não provocou um grande impacto sobre a atividade de vôo das colônias Pr2 e Pr3. Exceto uma atividade na colônia Pr1, às 14:00 horas, a porcentagem dc-dnc caiu gradualmente a partir das 11:00 horas, apesar do impacto relativo ao segundo pico de precipitação, às 16:00 horas.

Na primavera (Figura 4), até as 13:00 horas, a porcentagem dc-dnc geralmente foi positiva, com médias de 3,4 (Pr1), 10,4 (Pr2), 3,4 (Pr3) e 7,9 (Pr4). A precipitação, entre as 14:00 e 17:00 horas, causou uma diminuição destes números: $-21,8(\operatorname{Pr} 1),-10,8(\operatorname{Pr} 2),-4,2(\operatorname{Pr} 3)$ e -1,9 (Pr4). A partir das 18:00 horas, a porcentagem dc-dnc aumentou, com médias de 193,4 (Pr1), -4,8 (Pr2), 19,2 (Pr3) e 0,1 (Pr4). Os últimos pontos da colônia P1: 358,3 e 687,5 foram omitidos das Figuras 3 e 4, já que as modificariam de uma maneira tal, que as gradações dos outros pontos não seriam mais percebidas.

De maneira geral, os picos de precipitação total corresponderam às menores porcentagens dc-dnc. No outono e, notadamente, no inverno, os dias chuvosos foram bem diferentes dos não chuvosos, independente da precipitação total, com porcentagens dc-dnc geralmente abaixo de $0 \%$.

Em dias com chuva contínua, durante todo o horário de forrageamento, a atividade de vôo sofreu forte redução. Em 06/01/99 (verão), a atividade de vôo das colônias reduziu-se em: 71,8\% (col. Pr1), 23,9\% (col. Pr2), 42,0\% (col. Pr3) e 43,8\% (col. Pr4). No dia 20/06/99, as reduções da atividade de vôo foram elevadas: 100,0\% (col. Pr1), 78,0\% (col. Pr2), 72,7\% (col. Pr3) e 83,0\% (col. Pr4).

\section{Diferenças entre as colônias}

Os testes de Tukey para comparações múltiplas mostraram que as colônias Pr2, Pr3 e Pr4 não foram estatisticamente diferentes em suas atividades de vôo em dias com intensidade de chuva até $1,0 \mathrm{~mm}$ (Pr2 vs. $\operatorname{Pr} 3, \mathrm{p}=0,988 ; \operatorname{Pr} 2$ vs. $\operatorname{Pr} 4, \mathrm{p}=0,653 ; \operatorname{Pr} 3$ vs. $\operatorname{Pr} 4, \mathrm{p}=0,713$ ); entre 1,0 e $10,0 \mathrm{~mm}(\operatorname{Pr} 2$ vs. $\operatorname{Pr} 3, \mathrm{p}=0,997 ; \operatorname{Pr} 2$ vs. $\operatorname{Pr} 4, \mathrm{p}=0,873$; $\operatorname{Pr} 3$ vs. $\operatorname{Pr} 4, \mathrm{p}=0,896)$; acima de 10,0 mm (Pr2 vs. $\operatorname{Pr} 3, \mathrm{p}=0,909$; $\operatorname{Pr} 2$ vs. $\operatorname{Pr} 4, \mathrm{p}=0,957 ; \operatorname{Pr} 3$ vs. $\operatorname{Pr} 4, \mathrm{p}=0,799)$. Por outro lado, em dias sem chuva, somente $\operatorname{Pr} 2$ e Pr3 não foram significantemente diferentes $(p=0,772)$.

\section{Discussão}

A redução na atividade de vôo de Plebeia remota, uma hora antes da ocorrência da chuva demonstra uma capacidade de percepção de mudança nas condições climáticas, como fora predito por Roubik (1989). Ele argumentou a possibilidade das abelhas detectarem mudanças na umidade e na pressão barométrica, que lhes permitiriam prever a chegada da chuva. Kleinert-Giovannini (1982) observou uma redução na atividade de vôo de Plebeia emerina, quando o céu passou de ensolarado a encoberto, apesar da temperatura permanecer constante, o que permitia o forrageamento. Em Apis mellifera, o aparecimento de nuvens de chuva provocou a seleção de recursos em locais mais próximos das colônias (Roubik 1989). Dentre as variáveis climáticas (Tabela 2), a umidade relativa foi a que teve relação mais estreita (maiores coeficientes de correlação de Spearman) com a pluviosidade, e cuja mudança poderia ser detectada pelas forrageiras de $P$. remota.

Roubik (1989) observou que o súbito aparecimento de nuvens de chuva no céu pareceu causar o rápido retorno das abelhas aos seus ninhos, embora ele tenha observado forrageamento durante a ocorrência de garoa, em vários gêneros de abelhas. Nas abelhas sem ferrão, a precipitação pluviométrica pode causar a interrupção da atividade de vôo, como foi observado por Oliveira (1973) em Plebeia droryana e $P$. saiqui, por Iwama (1977) em Tetragonisca angustula e por Kleinert-Giovannini (1982) em P. emerina.

Entretanto, Nogueira-Neto et al. (1959) observando a coleta de pólen e néctar em cafeeiros, assinalaram a presença de A. mellifera, Plebeia sp. e Nannotrigona testaceicornis, durante condições relativamente adversas: chuva ou céu encoberto e temperaturas de 19 a $20^{\circ} \mathrm{C}$. Kajobe \& Echazarreta (2005) também relataram o forrageamento de Meliponula nebulata sob condições de neblina e garoa. Em análise quantitativa, Buriolla (1988) relatou a redução de $22 \%$ em média na atividade de vôo de A. mellifera durante chuva. Assim, não foi surpresa a ocorrência de atividade de vôo de $P$. remota durante a chuva, embora com decréscimos significativos nas colônias observadas.

Após a ocorrência de chuva, houve acréscimos na atividade de vôo de todas as colônias de $P$. remota, com números que indicam uma tentativa de compensação no forrageamento em relação às horas que antecederam, e mesmo durante a precipitação. Oliveira (1973), Iwama (1977) e Kleinert-Giovannini (1982) mencionaram que após a cessação da chuva, a atividade de vôo das abelhas sem ferrão por elas estudadas voltou ao normal. Contudo, foi necessário que os outros fatores climáticos estivessem propícios ao vôo. Kleinert-Giovannini \& Imperatriz-Fonseca (1986) relataram a saída imediata de forrageiras de Melipona marginata marginata e M. m. obscurior, após o término da chuva. Pompeu \& Silveira (2002) relataram que em Melipona rufiventris, a compensação também ocorreu e ela foi relacionada a um maior número de viagens por abelha, preferentemente a um maior número de operárias realizando a atividade de forrageamento. 
Percepção instantânea pelas forrageiras de P. remota, de que o clima no dia mudaria logo, parece ter ocorrido no outono e se refletiu no decréscimo da atividade de vôo de todas as colônias, uma hora antes da chuva (Tabela 1). Por outro lado, a maior compensação de atividade de vôo, em quase todas as colônias, ocorreu na primavera. Além da umidade relativa, outros fatores climáticos pareceram atuar nestes eventos. Assim, a correlação negativa entre a radiação e a precipitação pode indicar que o céu esteve encoberto no outono e na primavera. $\mathrm{O}$ inverno e o verão foram as estações com a menor e a maior precipitação total, respectivamente, e suas relações com a temperatura podem ter sido bem diferentes. No inverno, as baixas temperaturas restringiram a atividade de vôo, enquanto que no verão, esta restrição ocorreu quando as temperaturas foram demasiado elevadas.

As estações também tiveram precipitações pluviométricas com diferenças em intensidade, freqüência e duração, que influenciaram, de maneira distinta, a atividade de vôo. Além dos fatores climáticos, não pode ser negligenciada a disponibilidade de recursos. A maior quantidade de flores na primavera, com maior oferta de pólen e néctar, pode ter impelido a atividade de vôo das abelhas depois da chuva. No verão, ocorreram precipitações com intensidade, freqüência e duração maiores do que as outras estações. Assim, a atividade de vôo pode ter sido reduzida até um patamar e, depois da chuva, qualquer atividade pode ter resultado em porcentagens baixas de acréscimos ou decréscimos.

As forrageiras de $P$. remota diminuíram sua atividade de vôo, antes e durante a chuva, ao mesmo tempo em que a intensidade da precipitação aumentou. Com exceção da colônia Pr1, as campeiras foram pouco afetadas por chuvas muito leves, com intensidade até $1 \mathrm{~mm}$. Michener (1974) relatou que Bombus pode forragear em condições menos favoráveis às outras espécies, sob chuva leve ou até mesmo neve. Morse (1982) assinalou que a atividade de vôo de Bombus pára, se a chuva for pesada, e que o forrageio em chuva leve ou garoa é possível, desde que clima rigoroso tenha o precedido e que os suprimentos na colônia estejam esgotados. Kleinert-Giovannini \& Imperatriz-Fonseca (1986) verificaram que a atividade de vôo de M. m. marginata e M. m. obscurior foram reduzidas consideravelmente por chuva muito leve ou garoa, e interrompida completamente quando ocorreu chuva pesada. Nossa classificação de intensidade de chuva foi subjetiva, mas não muito diferente de outras adotadas. Alguns autores consideram que, além do granizo e da neve, a precipitação pluviométrica pode ser classificada como: garoa (até $1,0 \mathrm{~mm} / \mathrm{h}$ ), chuva leve (até $2,5 \mathrm{~mm} / \mathrm{h}$ ), chuva moderada $(2,6$ a $7,5 \mathrm{~mm} / \mathrm{h}$ ) e chuva pesada (superior a 7,5 mm/h) (Hewlett \& Nutter 1969).

A atividade de vôo de $P$. remota foi mais afetada quando a chuva ocorreu apenas uma vez por dia. Saraiva (1985) observou que o padrão de atividade de vôo de A. mellifera foi prejudicado em um dia encoberto e frio $\left(17,2-19,6^{\circ} \mathrm{C}\right)$, no qual ocorreram chuvas antes das 08:00 horas e entre 14:00 e 16:00 horas. Houve baixa atividade de vôo de manhã e à tarde, com um aumento ao redor do meio dia.

Chuvas duradouras (mais de uma hora) causaram maior restrição à atividade de vôo de $P$. remota . Sommeijer et al. (1983) observaram que uma garoa de curta duração, logo pela manhã, retardou a coleta de pólen e que a chuva contínua causou uma queda nas atividades de vôo de Melipona favosa.

O padrão diário de atividade de vôo de $P$. remota parece ter sido afetado segundo a hora de ocorrência da chuva. Assim, tanto o maior prejuízo, como a maior compensação da atividade de vôo, ocorreu de manhã e diminuíram ao longo do dia, apesar das precipitações mais elevadas terem acontecido à tarde. A Tabela 1 foi elaborada a partir da análise, evento por evento, dos efeitos da chuva sobre a atividade de vôo de $P$. remota. Por outro lado, a análise global fornecida pelas Figuras 1 a 4, permitiu a verificação do prejuízo causado pela preci- pitação sobre o padrão diário da atividade de vôo. Ali pudemos verificar também, quedas na porcentagem dc-dnc antes da precipitação, o prejuízo relativo à ocorrência da chuva e também, a compensação da atividade de vôo, depois da chuva. Além disto, podemos ver que a atividade de vôo de $P$. remota em dias chuvosos dos meses mais frios (outono e inverno) foi bem diferente da atividade de vôo em dias não chuvosos das mesmas estações.

Liu et al. (1990) relataram que o número de vôos de A. mellifera em um dia chuvoso foi cerca de $20 \%$ do número de vôos em um dia ensolarado. Souza et al. (2006) observaram que a menor atividade de vôo de forrageiras de Melipona asilvai ocorreu no mês mais chuvoso entre os dez meses de estudo.

As comparações múltiplas mostraram que as colônias Pr4, e principalmente, Pr2 e Pr3 não diferiram estatisticamente entre si. Isto mostra que as abelhas das duas localidades respondem de modo similar à precipitação. Na literatura há sugestões de que a linhagem africanizada de $A$. mellifera forrageia em chuva leve, enquanto que raramente a européia faz isto (Roubik 1989).

Por outro lado, o número de vôos foi um indicativo fiel do tamanho das colônias e o impacto da precipitação sobre a atividade de vôo das colônias foi um reflexo disso. Durante boa parte do experimento, o número de vôos de Pr4 foi maior do que o número de vôos das colônias Pr2 e Pr3 que se equivaleram, e estes sempre foram bem maiores do que o número de vôos da colônia Pr1. Assim, o efeito da chuva na atividade externa de $P$. remota foi maior na colônia de menor tamanho (Pr1), do que nas maiores. Saraiva (1985) observou que as colônias fracas de A. mellifera foram mais susceptíveis às condições climáticas, incluindo chuva, que colônias fortes.

A atividade de vôo de Plebeia remota é influenciada pelas características da precipitação pluviométrica, além de outros fatores climáticos, mas não podemos descartar que a necessidade e a disponibilidade de recursos norteiam o forrageamento. Apesar da especiação, tanto as populações de Cunha, SP como de Prudentópolis, PR, são bem adaptadas aos seus hábitats, onde conviver com a chuva é uma regra.

\section{Agradecimentos}

Os autores agradecem à M.Sc. Patrícia Nunes-Silva, ao Dr. Felipe Andrés Leon Contrera e aos dois referees anônimos por seus valiosos comentários e sugestões. Nós também agradecemos pelo apoio financeiro provido pelo CNPq (140169/2000-8 ao SDH e 522121/97 à VLIF).

\section{Referências Bibliográficas}

ARIAS, M.C., FRANCISCO, F.O. \& SILVESTRE, D. 2003. O DNA mitocondrial em estudos populacionais e evolutivos de meliponíneos. In Apoidea Neotropica (G.A.R. Mello \& I. Alves-dos-Santos, eds.). Universidade do Extremo Sul Catarinense, Criciúma, p. 305-309.

AZEVEDO, G.G. 1996. Atividade de vôo e determinação do número de ínstares larvais em Partamona helleri (Friese) (Hymenoptera, Apidae, Meliponinae). Dissertação de Mestrado, Universidade Federal de Viçosa, Minas Gerais.

BELLUSCI, S. \& MARQUES, M.D. 2001. Circadian activity rhythm of the foragers of a eusocial bee (Scaptotrigona aff depilis, Hymenoptera, Apidae, Meliponinae) outside the nest. Biol. Rhythm Res. 32:117-124.

BENTHEM, F.D.J. van, Imperatriz-Fonseca, V.L. \& Velthuis, H.H.W. 1995. Biology of the stingless bee Plebeia remota (Holmberg): observations and evolutionary implications. Insect. Soc. 42:71-87.

BIESMEIJER, J.C. \& TÓTH, E. 1998. Individual foraging, activity level and longevity in the stingless bee Melipona beecheii in Costa Rica (Hymenoptera, Apidae, Meliponinae). Insect. Soc. 45:427-443.

BORGES, F. VON B. \& BLOCHTEIN, B. 2005. Atividades externas de Melipona marginata obscurior Moure (Hymenoptera, Apidae), em 
distintas épocas do ano, em São Francisco de Paula, Rio Grande do Sul, Brasil. Rev. Bras. Zool. 22:680-686.

BRUIJN, L.L.M. DE \& SOMMEIJER, M.J. 1997. Colony foraging in different species of stingless bees (Apidae, Meliponinae) and the regulation of individual nectar foraging. Insect. Soc. 44:35-47.

BRUIJN, L.L.M. DE, HERK, M.J. VAN \& SOMMEIJER, M.J. 1991. Some observations on flight activity and foraging of workers of the stingless bee Melipona favosa (Apidae, Meliponinae) in a large greenhouse. Acta Hort. 282:116-120.

BURIOLLA, A.H. 1988. Uso de método eletrônico (Apidômetro) na padronização do registro de atividades campeiras das abelhas, sob diferentes condições climáticas, como subsídio a genética do comportamento das abelhas africanizadas. In Pesquisas com Abelhas no Brasil. Brazilian Bee Research (A.E.E. Soares \& D. de Jong, eds.). Revista Brasileira de Genética, Ribeirão Preto, p. 73-74.

CONTRERA, F.A.L., IMPERATRIZ-FONSECA, V.L. \& NIEH, J.C. 2004. Temporal and climatological influences on flight activity in the stingless bee Trigona hyalinata (Apidae, Meliponini). Rev. Tecnol. Ambiente 10:35-43.

CORTOPASSI-LAURINO, M., VELTHUIS, H.H.W. \& NOGUEIRA-NETO, P. 2007. Diversity of stingless bees from the Amazon forest in Xapuri (Acre), Brazil. Proc. Exp. Appl. Entomol. 18:105-114.

CUNHA, R.S., SARAIVA, A.M., CUGNASCA, C.E., HIRAKAWA, A.R., Imperatriz-Fonseca, V.L. \& Hilário, S.D. 2001. An internet-based monitoring system for behaviour studies of stingless bees. In Proceedings of the Third European Conference of the European Federation for Information Technology in Agriculture, Food and the Environment (J. Steffe, ed.). EFITA, Montpellier, v.1, p. 279-284.

DANKA, R.G. \& BEAMAN, L.D. 2007. Flight activity of USDA-ARS Russian honey bees (Hymenoptera: Apidae) during pollination of lowbush blueberries in Maine. J. Econ. Entomol. 100:267-272.

ELLIS, J.D., HEPBURN, R., DELAPLANE, K.S., NEUMANN, P. \& ELZEN, P.J. 2003. The effects of adult small hive beetles, Aethina tumida (Coleoptera: Nitidulidae), on nests and flight activity of Cape and European honey bees (Apis mellifera). Apidologie 34:399-408.

ELTZ, T. \& VONEND, G. 2001. Battery-driven multi-channel event logger for monitoring social insect foraging in field situations. In Proceedings of the 2001 Berlin Meeting of the European Sections of IUSSI (R. Menzel \& E. Rademacher, eds.). p. 39.

FIDALGO, A.O. \& KLEINERT, A.M.P. 2007. Foraging behavior of Melipona rufiventris Lepeletier (Apinae; Meliponini) in Ubatuba, SP, Brazil. Braz. J. Biol. 67:137-144.

FOWLER, H.G. 1979. Responses by a stingless bee to a subtropical environment. Rev. Biol. Trop. 27:111-118.

FRANCISCO, F.O. 2002. Diversidade genética de populações da abelha sem ferrão Plebeia remota: análise do DNA mitocondrial e microssatélites. Dissertação de Mestrado, Universidade de São Paulo, São Paulo.

HEWLETT, J.D. \& NUTTER, W.L. 1969. An Outline of Forest Hydrology. University of Georgia Press. Athens.

HEARD, T.A. \& HENDRICKZ, J.K. 1993. Factors influencing flight activity of colonies of the stingless bee Trigona carbonaria (Hymenoptera, Apidae). Austr. J. Zool. 41:343-353.

HILÁRIO, S.D. \& IMPERATRIZ-FONSECA, V.L. 2002. Seasonality influence on flight activity of Plebeia pugnax Moure (in litt.) (Hymenoptera, Apinae, Meliponini). Naturalia 27:115-123.

HILÁRIO, S.D., GIMENES, M. \& IMPERATRIZ-FONSECA, V.L. 2003. The influence of colony size in diel rhythms of flight activity of Melipona bicolor Lepeletier (Hymenoptera, Apidae, Meliponini). In Apoidea Neotropica (G.A.R. Mello \& I. Alves-dos-Santos, eds.). Universidade do Extremo Sul Catarinense, Criciúma, p. 191-197.

HILÁRIO, S.D., IMPERATRIZ-FONSECA, V.L. \& KLEINERT, A.M.P. 2000. Flight activity and colony strength in the stingless bee Melipona bicolor bicolor (Apidae, Meliponinae). Rev. Bras. Biol. 60:299-306.
HILÁRIO, S.D., IMPERATRIZ-FONSECA, V.L. \& KLEINERT, A. DE M.P. 2001. Responses to climatic factors by foragers of Plebeia pugnax Moure (in litt.) (Apidae, Meliponinae). Rev. Bras. Biol. 61:191-196.

HUANG, M.H. \& SEELEY, T.D. 2003. Multiple unloadings by nectar foragers in honey bees: a matter of information improvement or crop fullness? Insect. Soc. 50:330-339.

IMPERATRIZ-FONSECA, V.L., KLEINERT-GIOVANNINI, A. \& PIRES, J.T. 1985. Climate variations influence on the flight activity of Plebeia remota Holmberg (Hymenoptera, Apidae, Meliponinae). Rev. Bras. Entomol. 29:427-434.

INOUE, M.N., YOKOYAMA, J. \& WASHITANI, I. 2007. Displacement of Japanese native bumblebees by the recently introduced Bombusterrestris (L.) (Hymenoptera: Apidae). J. Insect Conserv. http://www.springerlink. com/content/93v14102g26740n4 (último acesso em 29/08/2007).

INOUE, T., SALMAH, S., ABBAS, I. \& YUSUF, E. 1985. Foraging behavior of individual workers and foraging dynamics of colonies of three Sumatran stingless bees. Res. Popul. Ecol. 27:373-392.

IWAMA, S. 1977. A influência dos fatores climáticos na atividade externa de Tetragonisca angustula (Apidae, Meliponinae). Bol. Zool. Univ. S. Paulo 2:189-201.

KAJOBE, R. \& ECHAZARRETA, C.M. 2005. Temporal resource partitioning and climatological influences on colony flight and foraging of stingless bees (Apidae, Meliponini) in Ugandan tropical forests. Afr. J. Ecol. 43:267-275.

KLEINERT-GIOVANNINI, A. 1982. The influence of climatic factors on flight activity of Plebeia emerina Friese (Hymenoptera, Apidae, Meliponinae) in winter. Rev. Bras. Entomol. 26:1-13.

KLEINERT-GIOVANNINI, A. \& IMPERATRIZ-FONSECA, V.L. 1986. Flight activity and responses to climatic conditions of two subspecies of Melipona marginata Lepeletier (Apidae, Meliponinae). J. Apic. Res. 25:3-8.

LACERDA, L.M., ZUCCHI, R. \& ZUCOLOTO, F.S. 1991. Colony condition and bionomic alterations in Geotrigona inusitata (Apidae, Meliponinae). Acta Biol. Paranaense 20:109-123.

LIU, C., LEONARD, J.J. \& FEDDES, J.J. 1990. Automated monitoring of flight activity at a beehive entrance using infrared light sensors. J. Apic. Res. 29:20-27.

LUNDIE, A.E. 1925. The flight activities of the honeybee. U. S. Dep. Agric. Bull. 1328:1-37.

MICHENER, C.D. 1974. The Social Behavior of the Bees: A Comparative Study. The Belknap Press of Harvard University Press, Cambridge.

MICHENER, C.D. 2000. The Bees of the World. The John Hopkins University Press, Baltimore.

MOHAMMED, F. \& STARR, C.K. 1999. Comparative foraging of the sympatric stingless bees Trigona nigra and Partamona nigrior (Apidae: Meliponini). Proc. Exp. Appl. Entomol. 10:195-202.

MORSE, D.H. 1982. Behavior and ecology of bumble bees. In Social Insects (H.R. Hermann, ed.). Academic Press Inc., New York, v.3, p.245-322.

MOUGA, D.M.D.S. 1984. Atividade de coleta de Paratrigona subnuda Moure (Apidae, Meliponinae). In Pesquisas com Abelhas no Brasil. Brazilian Bee Research (A.E.E. Soares \& D. de Jong, eds.). Revista Brasileira de Genética, Ribeirão Preto, p.322-324.

NAGAMITSU, T \& INOUE, T. 2002. Foraging activity and pollen diets of subterranean stingless bee colonies in response to general flowering in Sarawak, Malaysia. Apidologie 33:303-314.

NOGUEIRA-NETO, P. 1970. A Criação de Abelhas Indígenas sem Ferrão. Editora Chácaras e Quintais, São Paulo.

NOGUEIRA-NETO, P., CARVALHO, A. \& ANTUNES FILHO, H. 1959. Efeito da exclusão dos insetos polinizadores na produção do café Bourbon. Bragantia 18:441-468.

NUNES-SILVA, P. 2007. A organização e a ritmicidade no forrageamento e na enxameação de Plebeia remota (Holmberg) (Hymenoptera, Apidae, Meliponini). Dissertação de Mestrado, Universidade de São Paulo, São Paulo. 
OLIVEIRA, M.A.C. 1973. Algumas observações sobre a atividade externa de Plebeia saiqui e Plebeia droryana. Dissertação de Mestrado, Universidade de São Paulo, São Paulo.

PATRÍCIO, E.F.L.R.A. \& IMPERATRIZ-FONSECA, V.L. 2004. S.E.M. and GC-MS studies of Plebeia remota (Hymenoptera, Meliponini). In Anais do VI Encontro Sobre Abelhas (K. Hartfelder, D. de Jong, R.A. Pereira, A. dos S. Cristino, M.M. Morais, E.D. Tanaka, A.P. Lourenço, J.E.B. da Silva, G.F. de Almeida \& A.M. do Nascimento, eds.). Faculdade de Filosofia Ciências e Letras de Ribeirão Preto, Ribeirão Preto, p. 739.

PICK, R.A. \& BLOCHTEIN, B. 2002. Atividades de vôo de Plebeia saiqui (Holmberg) (Hymenoptera, Apidae, Meliponini) durante o período de postura da rainha e em diapausa. Rev. Bras. Zool. 19:827-839.

PIERROT, L.M. \& SCHLINDWEIN, C. 2003. Variation in daily flight activity and foraging patterns in colonies of uruçu - Melipona scutellaris Latreille (Apidae, Meliponini). Rev. Bras. Zool. 20:565-571.

POMPEU, M.S. \& SILVEIRA, F.A. 2002. Variação mensal da atividade e número de abelhas campeiras de colônias de Melipona rufiventris (Meliponina: Apidae). In Anais do V Encontro Sobre Abelhas (C.A. Garofallo. \& G. Freitas, eds.). Faculdade de Filosofia Ciências e Letras de Ribeirão Preto, Ribeirão Preto, p. 321.

RIBEIRO, M.F., IMPERATRIZ-FONSECA, V.L. \& SANTOS-FILHO, P.S 2003. A interrupção da construção de células de cria e postura em Plebeia remota (Holmberg) (Hymenoptera, Apidae, Meliponini). In Apoidea Neotropica (G.A.R. Mello \& I. Alves-dos-Santos, eds.). Universidade do Extremo Sul Catarinense, Criciúma, p. 177-188.

ROUBIK, D.W. 1989. Ecology and Natural History of Tropical Bees. Cambridge University Press, New York.
ROUBIK, D.W. \& BUCHMANN, S.L. 1984. Nectar selection by Melipona and Apis mellifera (Hymenoptera: Apidae) and the ecology of nectar intake by bee colonies in a tropical forest. Oecologia 61:1-10.

SARAIVA, J.A.P.G. 1985. Bioclimatic factors affecting flights of honeybees, Apis mellifera L. (Hymenoptera: Apidae). In Pesquisas com Abelhas no Brasil. Brazilian Bee Research (A.E.E. Soares \& D. de Jong, eds.). Revista Brasileira de Genética, Ribeirão Preto, p. 399-400.

SOMMEIJER, M.J., de ROOY, G.A., PUNT, W. \& de BRUIJN, L.L.M. 1983. A comparative study of foraging behaviour and pollen resources of various stingless bees (Hym., Meliponinae) and honey bees (Hym., Apinae) in Trinidad, West-Indies. Apidologie 14:205-224.

SOUZA, B.A., CARVAlHO, C.A.L. \& ALVES, R.M.O. 2006. Flight activity of Melipona asilvai Moure (Hymenoptera: Apidae). Braz. J. Biol. 66:731-737.

SOUZA, J.L.F. DE \& GONÇALVES, L.S. 1994. Influência do aumento da temperatura e da luminosidade interna nas atividades de vôo de abelhas Apis mellifera scutelatta (africanizada) e sua relação com o comportamento enxameatório através do uso do registrador automático de atividades de vôo das abelhas: apidômetro. In Anais do I Encontro sobre Abelhas (R. Zucchi, P.M Drummond, G. Fernandes-da-Silva \& S.C. Augusto, eds.). Faculdade de Filosofia Ciências e Letras de Ribeirão Preto, Ribeirão Preto, p. 201-213.

SPAETHE, J. \& WEIDENMÜLLER, A. 2002. Size variation and foraging rate in bumblebees (Bombus terrestris). Insect. Soc. 49:142-146.

WOYKE, J. 1992. Diurnal flight activity of African bees Apis mellifera adansonii in different seasons and zones of Ghana. Apidologie 23:107-117.

ZAR, J.H. 1999. Biostatistical Analysis. 4 ed. Prentice-Hall, Upper Saddle River. 
